\title{
PROPERTIES OF SILICON DIOXIDE FILM DEPOSITED BY PECVD AT LOW TEMPERATURE/PRESSURE
}

\author{
Meysam Zarchi ${ }^{1 *}$, Shahrokh Ahangarani ${ }^{2}$, Maryam Zare Sanjari ${ }^{3}$ \\ 1*Department of Engineering, Dezful Branch, Islamic Azad University, \\ Dezful, Iran \\ ${ }^{2}$ Advanced Materials \& Renewable Energies Department, Iranian Research \\ Organization for Science and Technology, Tehran, Iran \\ ${ }^{3}$ Department of Mathematics, Dezful Branch, Islamic Azad University, \\ Dezful, Iran
}

Received 18.01.2014

Accepted 24.03.2014

\begin{abstract}
In this paper we report results on synthesis of thin films of silicon dioxide $\left(\mathrm{SiO}_{2}\right)$ using conventional plasma enhanced chemical vapor deposition (PECVD) at low temperature/pressure with silane $\left(\mathrm{SiH}_{4}\right)$ and nitrous oxide $\left(\mathrm{N}_{2} \mathrm{O}\right)$ as precursor gases. The ellipsometer and stress measurement system were used to test the thickness and refractive index uniformity of the $\mathrm{SiO}_{2}$ film fabricated. The effects of radio frequency (RF) power chamber pressure and $\mathrm{N}_{2} \mathrm{O} / \mathrm{SiH}_{4}$ flow ratio on the properties of $\mathrm{SiO}_{2}$ film were studied. The results show that the refractive index of $\mathrm{SiO}_{2}$ film is mainly determined by $\mathrm{N}_{2} \mathrm{O} / \mathrm{SiH}_{4}$ flow ratio .Moreover, the formation of $\mathrm{SiO}_{2}$ thin films is confirmed by Fourier transform infrared (FTIR) spectroscopy. The thickness and refractive indices of the films measured by ellipsometry $\mathrm{C}-\mathrm{V}$ measurement show that the electrical properties are directly related to process parameters and $\mathrm{Si} / \mathrm{SiO}_{2}$ interface. The MIS structures were also fabricated from optimized $\mathrm{SiO}_{2}$ layer to study $\mathrm{C}-\mathrm{V}$ measurement and to estimate interface, oxide and effective border traps density. The deposited $\mathrm{SiO}_{2}$ films have good uniformity, compact structure, high deposition rate, low deposition temperature and controllable stress, which can be widely, used in semiconductor devices.

Keywords: Thin Films; Silicon Dioxide; Plasma Enhanced Chemical Vapor Deposition (PECVD); Fourier transform infrared (FTIR) spectra; UV-Visible Spectroscopy; Ellipsometry.
\end{abstract}

\section{Introduction}

Silicon dioxide thin films are widely used in semiconductor device technology as gate insulators, for passivation and as intermetallic dielectric layers. These films are

*Corresponding author: Meysam Zarchi: sky_man1983@yahoo.com 
either thermally grown through the oxidation of silicon or deposited by thermal or plasma-enhanced

Chemical Vapor Deposition (PECVD). The advantage of PECVD is that low deposition temperatures can be used, avoiding defect formation in the underlying silicon substrate, dopant diffusion and degradation of the metal layers.

However, PECVD-prepared silicon dioxide films are usually affected by a high impurity concentration (hydrogen and nitrogen, $\mathrm{H}_{2} \mathrm{O}, \mathrm{Si}-\mathrm{OH}$ groups), and are characterized by a high porosity compared with those deposited at higher temperature [1]. To improve the quality of the deposited layers, PECVD processes can be optimized by varying some deposition (i.e. temperature, total and partial pressures, plasma power and frequency, etc.) and post-deposition (temperature and environment of the annealing process) parameters [2-4].

In this work, we present some results on the chemical and structural properties of $\mathrm{SiO}_{2}$ thin films prepared by PECVD from silane $\left(\mathrm{SiH}_{4}\right)$ and $\mathrm{N}_{2} \mathrm{O}$ precursors. We have mainly investigated the influence of the $\mathrm{N}_{2} \mathrm{O} / \mathrm{SiH}_{4}$ flow ratio by using Rutherford backscattering spectrometry (RBS), ellipsometry and infrared (IR) spectroscopy. The idea was to show that a variation of the $\mathrm{N}_{2} \mathrm{O} / \mathrm{SiH}_{4}$ flow ratio can influence not only, as expected, the composition of the deposited layers, but also their structure.

\section{Experimental}

The deposition processes were achieved in the FHR-PECVD 100 system. The structure of the system is illustrated in Fig.1. The system was equipped with both highfrequency $(13.56 \mathrm{MHz})$ and low-frequency $(300 \mathrm{kHz})$ powers for stress controlling but in our experiments only high-frequency power was used.

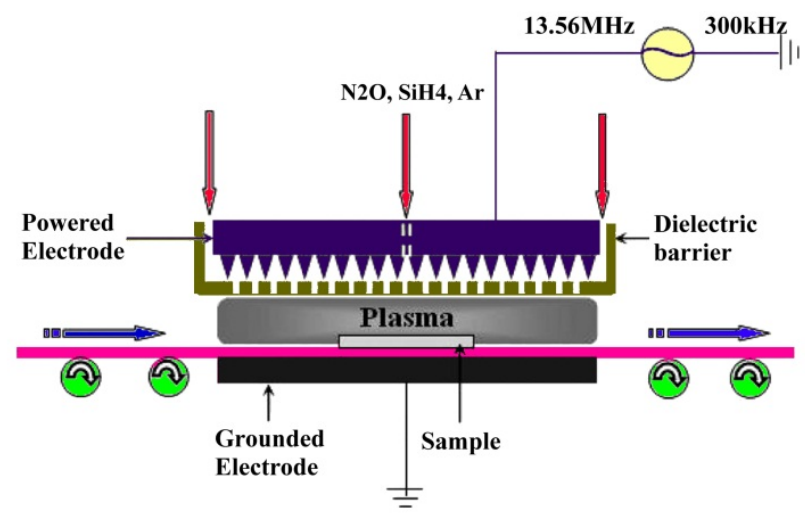

Fig.1. Schematic set up of PECVD system

The base pressure for predisposition was $1 \times 10^{-3} \mathrm{~Pa}$ and the process pressure was adjusted by a throttle valve. In order to obtain the exact temperature on the substrate in process mode, the thermocouple was placed on the substrate and the temperatures both on the heater and the substrate were obtained as shown in Fig.2. The chamber pressure was set to be $40 \mathrm{~Pa}$. The oxidation thickness and refractive index of the $\mathrm{SiO}_{2}$ films were measured by an ellipsometer Auto EL-AV. The stress of the film was obtained by the stress measurement system FLX-2320-S. 


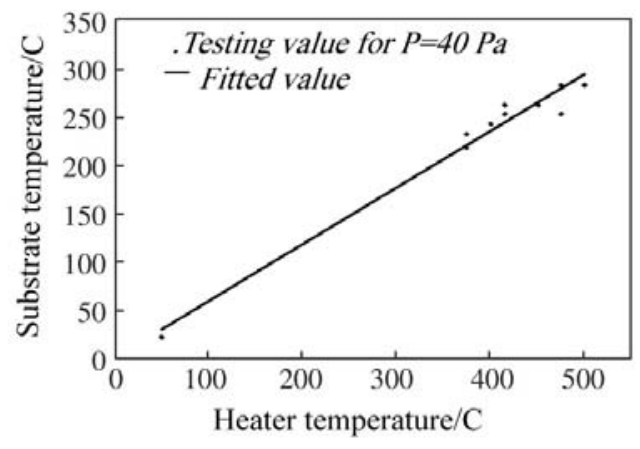

Fig.2. Temperature on the substrate and the heater

Fourier transform infrared (FTIR) spectra of the films were recorded by using FTIR spectrophotometer (JASCO, Japan). Bonded oxygen content (CO) was calculated from stretching mode of infra red (IR) absorption peak using the method proposed by Iftiquar [5]. The thickness of films is measured by using ellipsometery and was further confirmed by UV-Visible spectroscopy applying the method proposed by Swanepoel [6]. All samples were annealed at $450^{\circ} \mathrm{C}$ in ambient environment for $15 \mathrm{~min}$ and allowed to cool to the room temperature. After the substrate was loaded in the reaction chamber, it was baked for $20 \mathrm{~min}$ in the argon atmosphere to ensure the temperature

uniformity. The substrate temperature was fixed at $260{ }^{\circ} \mathrm{C}$ (the heater temperature was

$450^{\circ} \mathrm{C}$ ) and the side wall of the chamber was heated up to $50{ }^{\circ} \mathrm{C}$ in order to prevent $\mathrm{SiO}_{2}$

from depositing on the sidewall. $\mathrm{SiH}_{4}\left(25 \%\right.$ in volume, diluted by helium) and $\mathrm{N}_{2} \mathrm{O}$ were used as the precursor gases. The $\mathrm{N}_{2} \mathrm{O}$ flow was set to be $200 \mathrm{~cm}^{3} / \mathrm{min}$ and kept constant, and the $\mathrm{N}_{2} \mathrm{O} / \mathrm{SiH}_{4}$ flow ratio was regulated by adjusting $\mathrm{SiH}_{4}$ flow. The metalinsulator-semiconductor (MIS) structures were fabricated for capacitance-voltage (C-V) measurements and for interface characterization. The $\mathrm{C}-\mathrm{V}$ measurements were achieved with the inductance, capacitance, and resistance (LCR) meter by varying voltage from 3 to $3 \mathrm{~V}$ at $1 \mathrm{MHz}$ frequency. The operating variables were high frequency RF power, chamber pressure and $\mathrm{N}_{2} \mathrm{O} / \mathrm{SiH}_{4}$ flow ratio. For safety reason, the chamber and the gasoline must be flushed with argon more than 5 circles before getting the substrate out.

\section{Results}

Deposition of $\mathrm{SiO}_{2}$ film

The plot of deposition rate as a function of chamber pressure is shown in Fig. 3 at various units of radio-frequency (RF) power. The $\mathrm{SiH}_{4}$ flow was set to be the same for all samples, i.e. $55 \mathrm{~cm}^{3} / \mathrm{min}$ and was held constant. It is shown that with the increase of 
chamber pressure, the deposition rate first increased quickly and then the increase gradually slowed down. The higher the chamber pressure, the lower the change rate of the deposition rate.

This behavior may be explained considering that as the chamber pressure was increased, the concentration of the reactive gas rose, which accelerated the reaction process and the deposition rate. However, at higher chamber pressures, the ion collision was increased, and the energy reduced, which led to the slow increase of deposition rate.

Moreover, the deposition rate was increased with the increase of the RF power from 15 to $150 \mathrm{~W}$. It was the increased energy of the electrons produced by higher RF power that increased the dissociation of the reactant gases and thus the deposition rate.

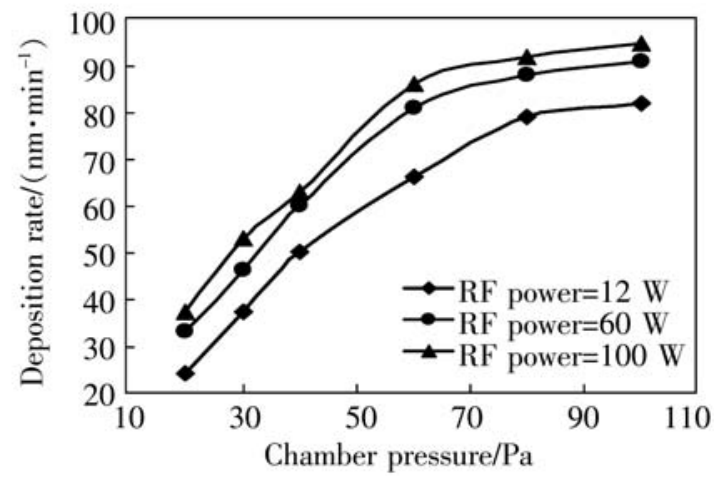

Fig.3. Variation of deposition rate of $\mathrm{SiO}_{2}$ film with chamber pressure and $\mathrm{RF}$ power

The deposition rate showed a maximum decrease trend as $\mathrm{SiH}_{4}$ flow increased, as illustrated in Fig.4. In this part, the RF power was set to be $60 \mathrm{~W}$, and the chamber pressure was $100 \mathrm{~Pa}$. It could be seen that the deposition rate was closely correlated with the $\mathrm{N}_{2} \mathrm{O} / \mathrm{SiH}_{4}$ flow ratio, which could be explained by the reaction theory, as shown in Eq. (1) [5].

$\mathrm{SiH}_{4}+2 \mathrm{~N}_{2} \mathrm{O} \rightarrow \mathrm{SiO}_{2}+2 \mathrm{~N}_{2}+\mathrm{H}_{2}$

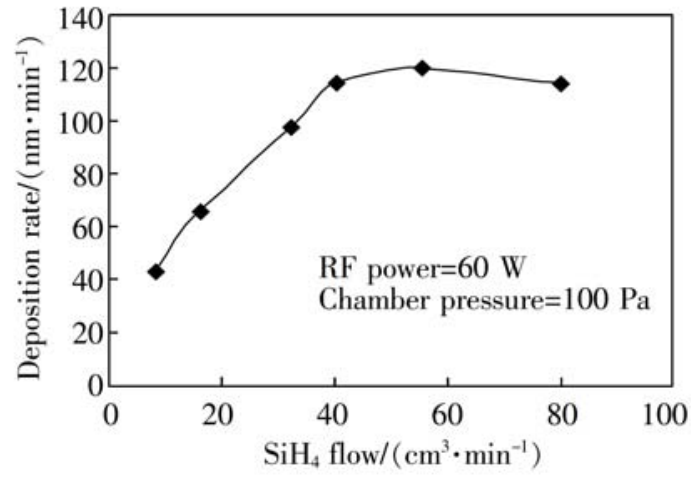

Fig.4. Deposition rate of $\mathrm{SiO}_{2}$ film as a function of $\mathrm{SiH}_{4}$ flow 
At first, by increasing the $\mathrm{SiH}_{4}$ flow, the number of $\mathrm{Si}$ based radicals was increased in the plasma with the increase of deposition rate. When the $\mathrm{SiH}_{4}$ flow was 55 $\mathrm{cm}^{3} / \mathrm{min}$, the deposition rate reached the maximum value of $120 \mathrm{~nm} / \mathrm{min}$. approximately

the $\mathrm{N}_{2} \mathrm{O} / \mathrm{SiH}_{4}$ flow ratio was 14:1, much higher than the theoretical value of $2: 1$.

This phenomenon could be attributed to the low dissolution rate of $\mathrm{N}_{2} \mathrm{O}$. Furthermore, when $\mathrm{SiH}_{4}$ flow was higher than $55 \mathrm{~cm}^{3} / \mathrm{min}$, white $\mathrm{SiO}_{2}$ powder, which was a kind of byproduct, was deposited on the chamber wall and observed in the pumping line after deposition process. Then the deposition rate began to decrease because precursors were consumed to form these particles.

FTIR spectroscopic analysis

The FTIR spectrum of $\mathrm{SiO}_{2}$ films deposited at various oxygen partial pressures $\left(\mathrm{PO}_{2}\right)$ by PECVD are shown in Fig. 5.

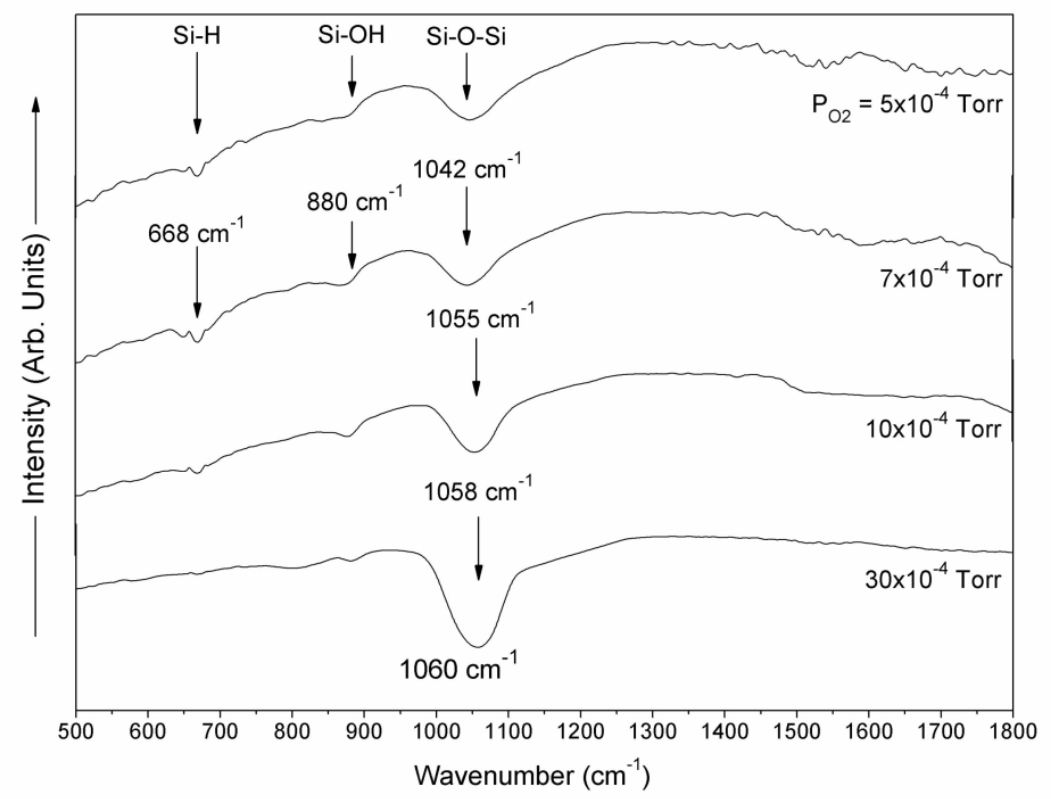

Fig. 5. FTIR transmission spectra of the series of samples deposited at different oxygen partial pressures. The spectra are arbitrarily shifted vertically for clarity

Taking into account the FTIR spectra for the films deposited at various oxygen partial pressures, observations are as follows:

- All films have major absorption bands at $\sim 668 \mathrm{~cm}^{-1}$ due to Si-O-Si bending vibrational mode [7], at $\sim 880 \mathrm{~cm}^{-1}$ due to bending vibrational mode of $\mathrm{Si}-\mathrm{OH}$ bonded species [8], and at $\sim 1042 \mathrm{~cm}^{-1}$ due to anisometric stretching vibrational mode of Si-O-Si [9]. 
- It can be clearly noticed that with increasing oxygen partial pressure, the intensity of absorption of band $\sim 1042 \mathrm{~cm}^{-1}$ increases and it shifts towards higher wave number. The increase in intensity absorption of band indicates increase in oxygen content in the films with increase in oxygen partial pressure in $\mathrm{SiH}_{4}$ and $\mathrm{H}_{2}$ plasma, whereas the shifting of absorption of band towards higher wave number indicates the formation of stoichiometric $\mathrm{SiO}_{2}[10]$.

- The presence of only one broad peak in Fig. 1 indicates that there is no hydrogen bonding present in the deposited films. This implies that $\mathrm{H}_{2} \mathrm{O}$ concentration in the film is very low. The relative peak intensity of Si-O bending to O-H bending further supports conjecture.

- Furthermore, appearance of weak absorption peak at $\sim 880 \mathrm{~cm}^{-1}$ in the FTIR spectra may be due to silanol which is formed due to unreacted silane, oxygen, and hydrogen in the plasma [9].

Therefore, the FTIR spectroscopic analysis clearly indicates the formation of $\mathrm{SiO}_{2}$ films using the silane and oxygen mixture by using PE-CVD technique.

\section{Ellipsometry analysis}

Fig. 6 shows the variation of static refractive index $\left(n_{0}\right)$ and deposition rate $\left(r_{d}\right)$ for $\mathrm{SiO}_{2}$ films deposited by PECVD as a function of oxygen partial pressure $\left(P_{\mathrm{O}_{2}}\right)$.

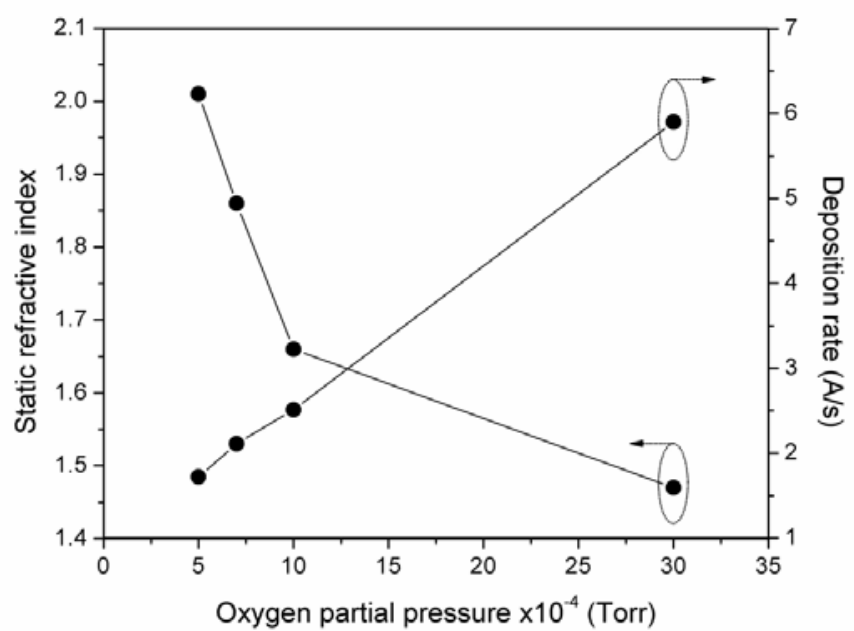

Fig. 6. Variation of static refractive index and deposition rate as a function of oxygen partial pressure for $\mathrm{SiO} 2$ thin films deposited by PECVD

As seen from the figure, the deposition rate of $\mathrm{SiO} 2$ films increases from 1.72 $\mathrm{A}^{\mathrm{o}} / \mathrm{s}$ to $5.90 \mathrm{~A}^{\mathrm{o}} / \mathrm{s}$ as oxygen partial pressure increases from $5 \times 10^{-4}$ to $30 \times 10^{-4}$ Torr. It was reasonable to expect the increase in deposition rate with increase in oxygen partial pressure. With increasing $P_{\mathrm{O} 2}$ the density of $\mathrm{O}_{2}$ in the deposition chamber increases. The $\mathrm{O}_{2}$ is highly reactive with silane. Thus, at the fixed deposition pressure and the plasma excitation power employed, the density of reactive precursors responsible for the growth of $\mathrm{SiO}_{2}$ increases with increase in $P_{O 2}$. As a result the deposition rate increases with increase in oxygen partial pressure. The abrupt increase in deposition rate for the $\mathrm{SiO}_{2}$ film deposited at $P_{O 2}=30 \times 10^{-4}$ Torr further supports this inference. 
Also, as seen from the same figure, the static refractive index for $\mathrm{SiO}_{2}$ films decreases from 2.01 to 1.47 as the oxygen partial pressure was increased from $5 \times 10^{-4}$ to $30 \times 10^{-4}$ Torr. It is interesting to note that the value of static refractive index for ultrathin $\mathrm{SiO}_{2}$ film having thickness of $88 \AA(1.47)$ is same as that of bulk $\mathrm{SiO}_{2}$. This result indicates that the dense $\mathrm{SiO}_{2}$ films exhibiting very similar optical characteristics that of bulk $\mathrm{SiO}_{2}$ can be obtained from PECVD technique using silane and oxygen mixture.

Capacitance-Voltage ( $C-V)$ measurements

Fig. 7 shows the high frequency $\mathrm{C}-\mathrm{V}$ measurement curves for the $\mathrm{SiO}_{2}$ film (thickness - $924 \AA$ ) before and after annealing.
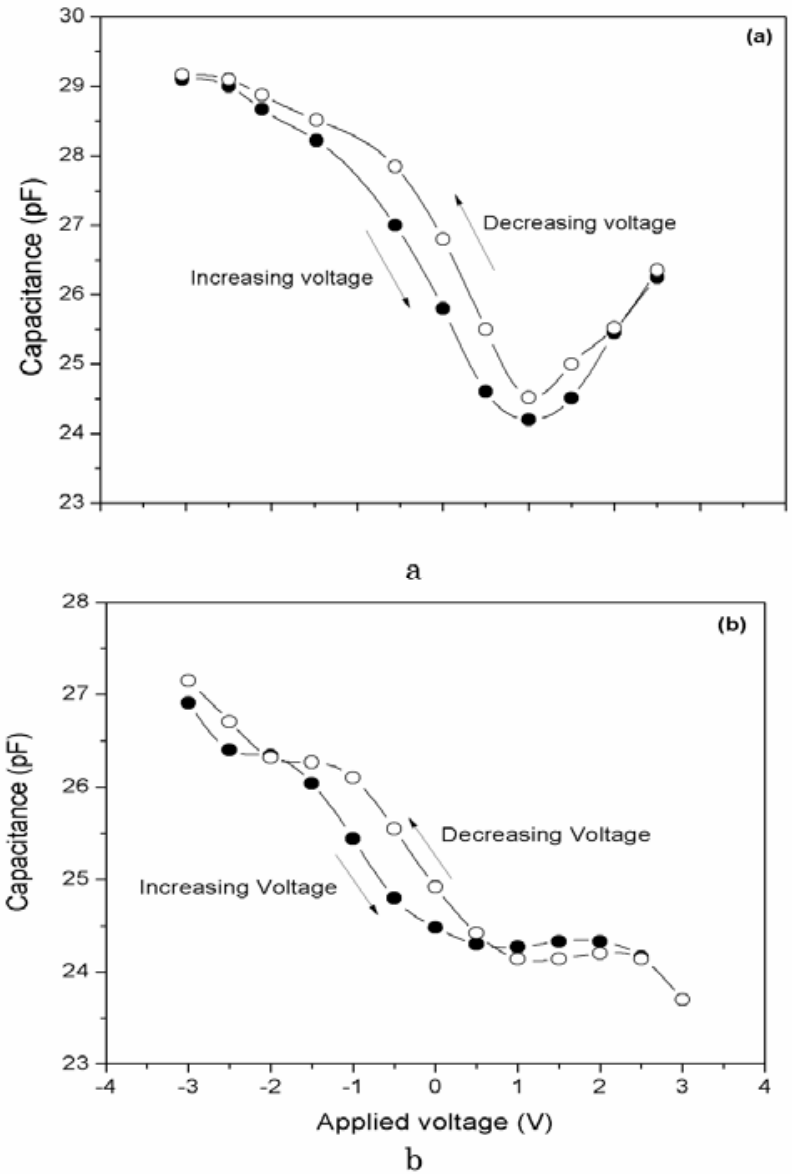

Fig. 7. The C-V plot for $\mathrm{SiO}_{2}$ film of thickness 924 A annealed (a) and unannealed (b) 
As seen from Fig. 7 a significant hysteresis is observed in $\mathrm{C}-\mathrm{V}$ plot for both annealed as well as unannealed films. This result shows the presence of border traps in the films. The estimated density of border trap (see Table 1) is agrees with previously reported values [11]. Furthermore, a jump like change in $\mathrm{C}-\mathrm{V}$ curve is observed for the unannealed film which is due to the effect of electric field during deposition of $\mathrm{SiO}_{2}$ film. Similar results have been observed for ultra-thin $\mathrm{SiO}_{2}$ films [12].

Table 1 Interface traps Qit, border traps Qbt and oxide traps Qot are calculated from $C$-V measurements. The corresponding thickness and refractive index measured from ellipsometry are also shown in this table

\begin{tabular}{|c|c|c|c|c|}
\hline $\begin{array}{c}\text { Sample } \\
\text { thickness }(\AA)\end{array}$ & Qit $\times 10^{12}$ & Qbt $\times 10^{11}$ & Qot $\times 10^{9}$ & $\begin{array}{c}\text { Refractive } \\
\text { index }\end{array}$ \\
\hline 88 & 1.5 & 3.0 & 5.32 & 1.47 \\
\hline 264 & 3.2 & 4.08 & 8.43 & 1.47 \\
\hline 924 & 3.9 & 4.56 & 24 & 1.47 \\
\hline 3940 & 2.5 & 0.88 & 1.35 & 1.48 \\
\hline
\end{tabular}

\section{Conclusion}

Silicon dioxide $\left(\mathrm{SiO}_{2}\right)$ films were successfully deposited by plasma enhanced chemical vapor deposition (PECVD) using silane and nitrous oxide $\left(\mathrm{N}_{2} \mathrm{O}\right)$ gas mixture. The effect of oxygen partial pressure on material properties has been investigated.

It is observed that the deposition rate increases with increase in RF power and gases partial pressure. The formation of $\mathrm{SiO}_{2}$ films has been confirmed by FTIR spectroscopic analysis. We observed that static refractive index and interface states for ultra-thin $\mathrm{SiO}_{2}$ film are the same as that of bulk $\mathrm{SiO}_{2}$. This result indicates that the ultrathin $\mathrm{SiO}_{2}$ film having device quality optical properties can be obtained from PECVD technique using silane and oxygen gas mixture.

\section{References}

[1] F. Fernandez-Lima, J.A. Rodriguez, E. Pedrero, H. D. Fonseca Filho, A. Llovera, M. Riera, C. Dominguez, M. Behar, F.C. Zawislak, Nucl Inst Met Phys Res B 243(1) (2006) 200-204.

[2] J.Y. Lee, S.W. Glunz Solar Energy Mat. Solar Cells 908 (1) (2006) 82-92.

[3] Y. Larionova, N.P Harder, R. Brendel, Proceedings 25th European Photovoltaic Solar Energy Conference. Valencia, Spain, 2010, 1-3.

[4] J.A. Rodriguez, C. Dominguez, F.J. Munoz, Proceedings of SPIE. Houghton, USA, 3953 (2000) 141-149.

[5] S.M. Iftiquar, J. Phys. D: Appl. Phys. 31 (1998) 1630-1641.

[6] R. Swanepoel, J. Phps. E: Sci. Instrum. 16 (1983) 1214-1222.

[8] M. Hino, T. Sato, Bull. Chem. Soc. Jap. 44 (1971) 33-39.

[9] J. Osswald, K.T. Fehr, J. Mat. Sci. 41 (2006) 1335-1339.

[10] P.G. Pai, S.S. Chao, Y. Takagi, G. Lucovsky, J. Vac. Sci. Technol. A 4 (3) (1986) 689-694.

[11] D.M. Fleetwood, N.S. Saks, J. Appl. Phys. 79 (1996) 1583-1594.

[12] E.A. Bobrova, N.M. Omeljanovskaya, Semiconductors 42 (2008) 1351-1354. 